\title{
Synthesis and structure of trans-[Rh(CO)(PPh $\left.)_{2}\left(\mathrm{NCBH}_{3}\right)\right]$
}

\section{Margarita R. Galding ${ }^{\mathrm{a}}$, Alexander V. Virovets ${ }^{\mathrm{bc}}$, Igor V. Kazakov ${ }^{\mathrm{a}}$, Manfred Scheer ${ }^{\mathrm{c}}$, Sergey N.} Smirnov a and Alexey Y. Timoshkin ${ }^{\text {a* }}$

anstitute of Chemistry, Saint-Petersburg State University, Universitetskaya nab. 7/9, St. Petersburg, 199034, Russian Federation

${ }^{b}$ Nikolaev Institute of Inorganic Chemistry, Siberian Division of RAS, Acad. Lavrentyev str. 3, Novosibirsk, 630090, Russian Federation

'Institut für Anorganische Chemie, Universität Regensburg, Universitätsstraße 31, Regensburg, 93053, Germany

Correspondence email: a.y.timoshkin@ spbu.ru

\section{Supporting information}

\section{S1. General experimental procedures}

All operations were carried out in atmosphere of dry argon using Schlenk techniques. All solvents were purified according to standard procedures. $\mathrm{CDCl}_{3}$ was washed with water, dried over $\mathrm{CaCl}_{2}$ and distilled over $\mathrm{CaH}_{2}$ before use. $\mathrm{NaBH}_{3} \mathrm{CN}$ was purchased from Aldrich and used as received. IR spectra were recorded with the Specord $75 \mathrm{IR}$ instrument ( $\mathrm{CaF}_{2}$ windows). NMR studies were performed at the Centre for Magnetic Resonance, St. Petersburg State University. The spectra were recorded on a Bruker spectrometer AVANCE III 400, at operating frequencies 400.13 MHz ( ${ }^{1} \mathrm{H}$ spectra), $100.61 \mathrm{MHz}\left({ }^{13} \mathrm{C}\left\{{ }^{1} \mathrm{H}\right\}\right)$ spectra), $161.97 \mathrm{MHz}\left({ }^{31} \mathrm{P}\left\{{ }^{1} \mathrm{H}\right\}\right)$ spectra and 128.38 MHz $\left({ }^{11} \mathrm{~B}\right)$ spectra in $\mathrm{CDCl}_{3}$ as solvent at $223 \mathrm{~K}$. The ${ }^{1} \mathrm{H}$ chemical shifts were referenced to TMS using solvent residual protons as internal standards, $7.26 \mathrm{ppm}$ for $\mathrm{CDCl}_{3}$; the ${ }^{13} \mathrm{C}$ chemical shifts were measured for samples with natural ${ }^{13} \mathrm{C}$ abundance and were referenced to TMS, using solvent ${ }^{13} \mathrm{C}$ as internal standard, $77.1 \mathrm{ppm}$ for $\mathrm{CDCl}_{3}$. The ${ }^{31} \mathrm{P}$ chemical shifts were measured with $85 \%$ phosphoric acid as external standard, $\delta{ }^{31} \mathrm{P} 0.0 \mathrm{ppm} .{ }^{11} \mathrm{~B}$ chemical shifts were externally referenced to $\mathrm{BF}_{3} \mathrm{OEt}_{2}\left(\delta^{11} \mathrm{~B} 0.00 \mathrm{ppm}\right)$. 